\title{
CIENCIA Y ESPACIOS PARA LAS MUJERES
}

Imelda Arana Sáenz ${ }^{*}$

\begin{abstract}
Por cierto, Dios ha dado la palabra a las mujeres. Y, jalabado sea!. Porque si la palabra de mujer fuera tan condenable como dicen algunos, Cristo no hubiera permitido que una mujer, María Magdalena, fuera la primera en anunciar el drama de su resurrección.
\end{abstract}

Cristine de Pizán ${ }^{171}$

\section{Prolegómeno crítico de mujeres a la sociedad patriarcal del conocimiento}

Hacer uso público de la palabra y reivindicar y reinterpretar con la palabra nuevos espacios para las mujeres fueron atrevimientos que se permitieron algunas mujeres del Medioevo, quienes decidieron enfrentar con la escritura la resistencia de la sociedad de entonces a que el sexo femenino hicieran tal cosa. Tales el caso de Cristine de Pizán, quien con su escrito La ciudad de las mujeres ejemplifica esa habilidad y hace posible reflexionar sobre la capacidad intelectual de algunas mujeres de la Edad Media, los temas que son de su interés en términos de conocimiento, sus críticas a la sociedad que las ultraja y las margina de las preocupaciones científicas, y sus aportes a la búsqueda de otras posibilidades para las mujeres.

En Cristine de Pizán esa búsqueda, en las condiciones penosas en que producía, la llevó a la elaboración de la utopía de soñar con una ciudad de las mujeres y para las mujeres. En el libro que lleva ese nombre, Cristine elabora diálogos imaginarios entre mujeres de diferente rango de sabiduría en los que denuncia documentos "científicos" como el Secreta Mulierum -opúsculo en que se hacen afirmaciones acerca de los grandes defectos en las funciones corporales de las mujeres- y hace caer en cuenta de que esos escritos de filósofos y sabios no son más que antologías de la mentira, que se toman como verdades debido a la autoridad de quien las enuncia, pues la realidad, basada en la propia experiencia corporal de las mujeres, indica lo contrario.

Este cuestionamiento, presentado en el escrito a manera de reflexión de una dama virtuosa que cuestiona las verdades que el poder masculino impone sin ningún basamento real sobre la naturaleza de las mujeres, se convierte en prolegómeno de lo que con los años se constituirá en la crítica de la ciencia hecha por las mujeres, en particular las denuncias de los sesgos de los estudios científicos adelantados sobre ellas en el campo de la biología, la medicina y la psicología.

La cantidad y calidad de los logros alcanzados, posteriormente, en ese terreno son el tema de investigación de Evelynn Hammonds (1996) y otras teóricas feministas de la ciencia y la llamada sociedad del conocimiento.

Evelynn menciona las denuncias de las biólogas acerca del tratamiento que hacen de las mujeres gran parte de las investigaciones biológicas, basadas en sesgos

\footnotetext{
* Magister en Sociología de la Educación de la Universidad Pedagógica Nacional y Master en Estudios de la Mujer de la Universidad de Barcelona (España). Coordinadora Académica del Colegio Distrital José Felix Restrepo.

${ }^{171}$ Citada por María Milagros Rivera, 1990, p. 191
} 
metodológicos e interpretativos de los estudios socioculturales de la feminidad y la masculinidad. Recoge el señalamiento de Lynda Birke acerca de la necesidad de que una nueva ciencia las incorpore como participantes activas y no meros objetos de estudio, pues los científicos han recurrido a la ciencia para reforzar teorías sobre la inferioridad de las mujeres y su incapacidad para la práctica de la ciencia.

Cristine, como antecesora de estas mujeres, ya se había pronunciado con energía sobre la necesidad de tal crítica, y había señalado cómo las «verdades» de la ciencia oficial -masculina - sobre las imperfecciones corporales de las mujeres hacen parte de otras "verdades» sobre las incapacidades de las mujeres en otros campos, y cómo en la mayor parte de los casos estos últimos se han tomado como efecto de los primeras, naturalizando y biologizando la diferencia sexual. Tal es el caso de los defectos a los cuales se refiere el opúsculo mencionado, según el cual el cuerpo de la hembra es una obra imperfecta conformada a su vez por la flaqueza o debilidad natural de la madre.

En la Ciudad de la mujeres, Cristine califica como mentira, disparate, estupidez, mala intención, engaño y falsedad lo dicho en ése y otros tantos escritos contra las mujeres, lo cual expresa la indignación que la impulsa a la utilización de la palabra escrita en forma de polémica discursiva verbal con la idea deque las ofensas públicas deben ser cobradas en público. Tal es el caso de su libro La Querella sobre Roman de la Rose, que escribe como respuesta ética y política al maltrato público hecho contra las mujeres.

En su trabajo sobre la querella, Helen Solterer (1995) afirma que ese recurso es una acusación contra el lenguaje literario difamatorio, que se convierte en la mecha que enciende una de las mayores controversias en Francia; en ella emplaza a Jean de Meun's Rose delante del público general y le exige respuesta. La Querella es una acusación por difamación convertida en un suceso movilizador de toda la comunidad, con el resultado de que sus palabras cimentan un cambio público espectacular. El movimiento creado modifica la disputa medioeval y da protagonismo a las mujeres. Por ser un caso de increpación que sobrepasa el estándar de la disputa clerical y académica, sitúa su confrontación en el centro del ámbito de lo ciudadano; envuelve a la comunidad clerical, a un círculo de prominentes humanistas de la vida intelectual parisina a comienzos del siglo XV y también a la ciudadanía. La polémica de Cristine critica la más alta tradición textual en la totalidad del espacio social y reivindica la ocupación y el usufructo de ese espacio.

Si se tiene en cuenta que en el Medioevo tardío el problema de difamación se localizaba en el dominio de lo público, si algún vituperio era conocido tenía que registrarse hacia afuera, ante las personas en su implícito papel de testigos; luego, creada públicamente, su evaluación debía darse solo en coro público. Este espectro de la adulación y la condenación públicas era más dañino en el caso de la reputación de las mujeres. Como depositarias del honor familiar y social y de su propio honor ellas fueron peculiarmente susceptibles de ataque.

Por lo tanto, el cargo de Cristine, además de clarificar la escena de la difamación, parangona un célebre trabajo literario como difamatorio del público. Esto es, encontró que la definición de mujer en Jean de Meun's Rose era injuriosa a la comunidad en su totalidad, al hablar de las mujeres como un elemento constitutivo del público. La difamación de las mujeres se convierte en materia de preocupación pública porque compromete a la totalidad del lenguaje que contribuye a definir una comunidad particular.

De igual manera, en la Ciudad de las mujeres se deja entrever la ignominia -mala intención- de los autores del opúsculo contra todos los hombres, al creerlos ingenuos y 
necios. Estas enérgicas defensas del punto de vista de la mujer son un acicate a la crítica feminista de la ciencia patriarcal, pues permiten construir un puente, buscar la genealogía, regresar a sus antecesoras. Ahora ya podemos encontrar nuevas y múltiples impugnaciones que van al fondo de las prácticas y teorías del denominado conocimiento científico.

Para asumir algunos de esos aportes, señalemos la crítica a lo que ha permitido que el estado de cosas denunciado se produzca: la división entre el trabajo emocional realizado por las mujeres y el trabajo intelectual realizado por los hombres. División que ha conducido a que la ciencia haya sido producida fundamentalmente por hombres blancos de clase media, causa y efecto a la vez de la influencia normativa de un ideal de masculinidad particular y, como efecto de ello, de la ignorancia sobre la influencia de fuerzas que, como la psique humana, actúan como condicionantes del conocimiento científico (Evelyn Fox Keller, 1991).

Entre los antecedentes de tal situación, Evelyn Fox Keller destaca la mitología proclamada con respecto a la brujería, a la cual se le ha asignado procedencia en la lascivia carnal insaciable de las mujeres, quienes en nombre de ella se han asociado con el demonio. En la Inglaterra del siglo XVII alcanzó su apogeo la difamación de las brujas y el temor hacia la sexualidad femenina; en ese escenario se puede observar cómo las agitaciones sociales y económicas se reflejan en una preocupación particularmente aguda por el género y la sexualidad, al vincular el exceso sexual femenino con el desorden y la desintegración sociales. A tenor de esas creencias en las brujas, se consolida la práctica de la ciencia como una aventura puramente masculina y casta en la que, en lugar de una unión, se busca el domino de la naturaleza femenina, con lo cual se consigue la derrota simultánea de la naturaleza y de lo femenino (Evelyn Fox, op. cit).

En el trabajo de Cristine se hace referencia a la intención de los autores «autorizados» de no permitir que las mujeres conozcan las afirmaciones hechas en su contra —al mantenerlas lejos de las letras-, previendo que ellas no podrían creer tales disparates y los podrían refutar. Con ello delatan el temor masculino al saber de las mujeres y la consecuente construcción del sistema ideológico patriarcal, que las margina de la ciencia pero las utiliza como objeto de estudio para la sustentación de tal sistema. Con base en ello, se construyen definiciones de masculino y femenino que se polarizan paulatinamente, hasta adecuarse totalmente, a la división cada vez mayor entre trabajo y hogar, tan necesaria al capitalismo industrial naciente. Desde el siglo XVII se impulsan nuevas características diferenciales entre la esfera de las mujeres y la de los hombres, y se opera una rigurosa reducción de las opciones económicas, políticas y sociales de que podían disponer las primeras. Para la separación de estas esferas fue fundamental la construcción de un nuevo ideal de feminidad, y el siglo XVII fue un punto de transición clave de esa transformación.

Para Evelyn Fox la revolución científica se apoya en este cambio. Se hace eco de tal división entre masculino y femenino, público y privado, trabajo y hogar, y opta por una polarización cada vez mayor de mente y naturaleza, razón y sentimiento, objetivo y subjetivo. Por tanto, la ideología de la ciencia moderna suministra a los hombres una nueva base para la autoestima y las proezas masculinas. «Dado el éxito de la ciencia moderna, definida en oposición a todo lo femenino, los temores a la Naturaleza y a la Mujer podrían apaciguarse. Reducida una a substrato mecánico y la otra a su virtud asexual, la esencia de la Materia podría ser amansada y conquistada a la vez; la potencia masculina quedaba confirmada» (Evelyn Fox, op. cit., p. 72). 
Un segundo elemento al que convocan los textos referidos de Cristine de Pizán es la utilización del poder y la autoridad, pues, como ha sido señalado por críticas y críticos de la ciencia, entre conocimiento y poder existe una fuerte relación, tanta, que quien tiene el poder define quién tiene la autoridad en la ciencia y el conocimiento en general; que el poder puede conducir a engaño y falsedad, tanto sobre el conocimiento como sobre las condiciones para acceder a él, y a que no existe, por consiguiente, autoridad femenina, ni genealogía femenina.

Al estudio de estos elementos se han dedicado personas como Evelyn Fox Kelly, quien anota que la ciencia moderna ha seguido las pautas señaladas por Bacon para la investigación científica; él, al parecer, fue el primero que estableció la ecuación entre conocimiento científico y poder y quien conceptuó que los propósitos de la ciencia debieran ser el control y la dominación de la naturaleza. Al percibir la ciencia como poder, el poder sobre la ciencia se constituye en paradigma y los hombres en los responsable de asumirlo y ejercerlo, lo cual ha significado un rechazo al acoplamiento de mente y forma propuesto por Platón y otros antecesores de Bacon, y, en última instancia, la negación de lo femenino como sujeto de la ciencia, negación que se ha tomado como característica del conocimiento científico.

Sin embargo, tal característica ha sido desmentida por mujeres audaces que, aun en circunstancias bastante adversas, han asumido la actividad científica como propia. María Milagros Rivera (1997) menciona entre ellas a Oliva Sabuco, Trótula, María de Francia, Eloisa, Teresa de Cartagena, Laura Cereta y otras a quienes les ha sido cuestionada la autoría de su obra. Por ejemplo, apenas publicada la Nueva filosofía, de Oliva Sabuco, su padre, Miguel de Sabuco, se declaró el autor, aun cuando no prosperó su diligencia.

Entre las cualidades de Oliva, María Milagros destaca que fue una autora independiente que propuso una reforma del mundo, de la filosofía y de la ciencia médica, basada en el conocimiento de sí, en el valor de la observación y de la experiencia y en el olvido de ciertos conocimientos académicos sustentados por la tradición de poder institucional; su experiencia les demostró los errores que hasta entonces se habían perpetuado y habían puesto en peligro, de manera permanente, la salud y la vida de la gente; de modo similar, Cristine adviene tanto sobre los peligros de engaño que se ciernen sobre los hombres y las mujeres con "esos disparates», como sobre la necesidad de basar el conocimiento en la propia experiencia.

María Milagros destaca cómo, paradójicamente, la autoría de Oliva es cuestionada en momentos en que en Europa y en España se alianza el proyecto de igualdad entre los sexos iniciado durante el humanismo, con el argumento de que una obra como la suya no podía haber sido escrita por una mujer. Lo que se evidencia es que su autoría fue percibida entonces como socialmente peligrosa porque, tal como lo señala la filósofa Diana Sartoti, "La relación con una mujer que sea percibida como autoridad reactiva el potencial iniciador y ordenador del principio materno, tanto frente al mundo como frente a la mujer que reconoce esa autoridad, haciendo así presente la autoridad de origen materno». Luego «la desautorización en el siglo XX de Oliva de Sabuco tiene que ver con un proyecto secular de cancelación de autoridad femenina y de genealogía materna, que es inherente al orden patriarcal; proyecto que tomó la forma de transformación de autoras en hombres, especialmente a partir del Humanismo, porque la concesión a las mujeres de nuevos derechos suele ir acompañada de la cancelación de antepasadas» (María Milagros Rivera, Op, cit., p. 145). 
Este modelo de producción intelectual, aun cuando recientemente se ha asumido como una práctica comprometida con la lucha de las mujeres como grupo social, fue adoptado desde entonces por varias autoras, unas reconocidas, otras anónimas, y en el caso particular de Oliva Sabuco es significativo que haya hecho explícito su sistema. No obstante, el feminismo va más allá al convertirlo en práctica política y en presupuesto conceptual de la construcción de autoridad femenina.

Así, por ejemplo, La Cigarini considera que se crea autoridad femenina a través de la ampliación de relaciones significativas entre mujeres, o sea, cuando una mujer usa una mediación femenina para relacionarse con el mundo. Esto origina sociedad femenina y autoridad femenina a partir del hecho de que una mujer recurre a otra para realizar su deseo; se trata de poder resaltar que una mujer tiene autoridad, como un estado presimbólico, pero teniendo en cuenta que la madre simbólica, genérico de lo femenino, no se encarna en nadie: es una riqueza a disposición de todas. Para Lia, el sujeto masculino se ha constituido porque ha pensado el mundo, pero el sujeto femenino se ha de constituir si piensa el mundo a partir de sí, de su práctica y de sus relaciones, colocándose en el centro.

El diálogo de La ciudad de las mujeres constituye un ejemplo de esa construcción de autoridad femenina mediante una relación significativa entre mujeres. Allí Cristine expresa la necesidad de esa mediación y asume la búsqueda de una autoridad femenina y de la genealogía femenina a través del recurso del sueño, en el cual hace presente la autoridad de origen materno, pues las damas que encarnan las virtudes son verdaderas autoridades y autoras de conocimiento y saber, y lo transmiten a Cristine y al resto de las mujeres por su intermedio.

\section{Naturalización de las mujeres o cultura vs. Naturaleza}

Los conceptos de la naturaleza y de la creación entran a hacer parte de la discusión de las damas en Cristine de Pizán. Sus razonamientos, aun cuando no cuestionan el contenido de los mitos eclesiásticos —en que también la ciencia se apoya- sobre la creación del hombre y de la mujer, son una prueba de la capacidad de conducción lógica de argumentos provenientes del discurso de los detractores de las mujeres, para demostrar las contradicciones y las debilidades arguméntales de los mismos. Ese ejercicio pone en primer plano la prueba de la experiencia misma. Es decir, se asume el juego racional de los filósofos y científicos varones para descubrir sus errores.

Tal es la característica de uno de los diálogos, en que se argumenta que habiendo sido hecho el hombre a imagen y semejanza de Dios, aquel debe ser reflejo de la divinidad, y por lo tanto, si Dios creó a la mujer de una parte del hombre, mal podría salir tan defectuosa y horripilante como se asevera, tanto por ser Dios el creador como por la sustancia de la que esta última es hecha.

Otro de los razonamientos que se pueden desprender de este diálogo se refiere a la Naturaleza, que resulta fuertemente degradada al ser degradado uno de sus productos, las mujeres. Hecho que podría ser considerado como un claro prolegómeno del papel asignado a la naturaleza por la ciencia formal. Algunos de los elementos del proceso que condujeron a ese papel ya han sido señalados, pero en favor de la discusión veamos algunos otros, que han sido aportados por las autoras a quienes nos estamos refiriendo.

Evelyn Fox proporciona tesis acerca de la importancia de Bacon en el nacimiento de una ciencia y una tecnología que tendrían el poder de transformar la relación del hombre 
con la naturaleza. Con él se pasa de una imagen de la relación mente-naturaleza de los alquimistas del Renacimiento y similar al coito, a la conjunción de mente y materia, a la fusión del masculino y el femenino, a un ideal metafórico del súper hombre viril, que busca la dominación (Evelyn Fox Keller, op. cit). Evelyn prosigue afirmando que si bien los alquimistas compartían el menosprecio que se sentía hacia las mujeres en aquella época, la capacidad procreadora de las mismas seguía siendo materia de reverencia, temor e incluso envidia: para Parecelso el mundo estaba poblado por los frutos de la mujer y por eso Dios le permitía vivir tanto tiempo, «por nauseabunda que Ella pueda ser». La capacidad paridora de la mujer era signo de bendición divina. En su opinión, la «imagen de Dios» se hallaba esculpida en la mujer del mismo modo que en el hombre (Ibid. p. 61).

Estos hechos permiten establecer un nexo entre las discusiones de las damas en Pizán y los debates oficiales sobre la naturaleza, las mujeres y lo divino. Cristine pensaba que las ideas sobre estos temas podrían cambiarse con una mejor comprensión práctica de las naturalezas complementarias de los hombres y las mujeres.

Pero siguiendo con Fox Keller, la meta de la nueva ciencia no es el intercambio metafísico sino la dominación, no es la unión de mente y materia sino el establecimiento del imperio del hombre sobre la naturaleza. El triunfo de aquellos que han sido agrupados, de un modo general, como filósofos mecánicos representó una derrota decisiva de la visión de la naturaleza y la mujer como algo divino y de una ciencia que, de acuerdo con ello, habría garantizado a ambas al menos cierto respeto. Tras haber dividido el mundo en dos partes, el que conoce — la mente - y lo cognoscible —la naturaleza -, la ideología científica prescribe entre ambas una relación de distancia y separación, un sujeto y un objeto totalmente divididos: la naturaleza es objetivada. «El maridaje legal y casto de Bacon es consumado por mediación de la razón más que del sentimiento, por mediación de la "observación" más que de la experiencia sensible "inmediata"». En concurrencia con la división del mundo entre sujeto y objeto, hay una división de las formas de conocimiento en objetivo y subjetivo. La mente científica se separa de lo que hay que conocer - la naturaleza-, y su autonomía queda garantizada al separar sus modos de conocer de aquellos otros en los que la dicotomía es amenazada (Evelyn Fox, op, cit, $p$. 87).

En razón de ello, Evelynn Hammonds, la crítica feminista de la ciencia, aboga por «una ciencia y una práctica científica que admitan la influencia de factores sociales; una ciencia que legitime el papel de las experiencias subjetivas de los/as investigadores/as (Evelynn Hammonds, op. cit., p. 139).

Nos encontramos, pues, ante la necesidad de un proyecto ya iniciado por mujeres de la talla de Cristine Pizán, en el que confluyen la reivindicación de las mujeres y sus prácticas científicas con la reivindicación de la naturaleza, la integridad del ser humano y, finalmente, la armonía universal. En La ciudad de las mujeres esa visión se proyecta mediante el primer diálogo en que Razón comunica a Cristine la llegada de la hora de la liberación para las mujeres con la ayuda de las virtudes laicas: Razón, Rectitud, Justicia, mediante la expulsión del mundo del error Las damas y demás mujeres podrán tener un lugar fortificado donde retirarse y defenderse contra tan numerosos agresores, pues hasta ahora los enemigos y palurdos han terminado por hacerse con la victoria en una guerra que han librado sin resistencia (María Milagros Rivera, 1990).

Objetividad y conocimiento científico 
Objetividad y subjetividad son quizás los conceptos que más relación han tenido con el debate ideológico que históricamente se ha planteado entre la ciencia y otros tipos de conocimiento o saber. Con el auge de las ciencias sociales se universaliza la categoría de ciencia y de lo denominado trabajo científico o investigación científica, con lo cual el debate objetividad-subjetividad adquiere nuevas connotaciones, al sumarse a él teóricos de diversas disciplinas. A ello se ha enlazado en las últimas décadas, la crítica feminista y. en general, las corrientes de pensamiento no androcéntrico, con nuevos y más finos elementos de análisis. Estos tienen como eje común la relación entre las prácticas científicas y las mujeres, con todas las aristas que pueden presentarse; algunas de las cuales han sido abordadas en la primera parte de este trabajo. Ahora la discusión se centrará en el concepto de objetividad y su contrapuesto, el de subjetividad, toda vez que se arraigan en la base de las prácticas científicas de las mujeres que han apostado su vida por subvertir un orden simbólico que ha constreñido sus capacidades cognitivas, pero que al hacerlo han tenido que meterse en el centro del mismo, con el riesgo de ser atrapadas por un estado de ambigüedad, caracterizado por la dificultad de mantener una esencia de mujer acorde con sus necesidades y deseos, entre su subjetividad femenina y su capacidad de objetividad.

Ese estado lo particulariza fielmente Amparo María Sarda (1993) cuando reseña la situación en que se encontró mientras elaboraba su tesis de doctorado. Su relato es tan contundente que conduce a pensar en todas las mujeres que han accedido al mundo de la academia y que frente a las demás han ganado mucho espacio, aunque, ¿a qué precio?

Por eso el tema de este trabajo se deriva de la necesidad que tienen las mujeres de ahondar en este tópico de la vida académica, que en lo personal es aguijoneado por la práctica profesional y por las concepciones de otras mujeres que, como Amparo, conmueven con sus relatos de vida.

En Amparo vemos con claridad la trampa en que se cae al pretender que existe una racionalidad científica mediante la cual, y solo mediante ella, es posible conocer y mejorar el mundo, pero que está disociada y escindida de la vida misma, al igual que, según la mitología, Zeus engendró sin intervención de mujer a la futura madre de los Ciudadanos de Atenas. Su experiencia de trabajo académico la enfrenta permanentemente a la vivencia de la distancia entre las teorías y las prácticas, con la que se tropieza cada día mediante la encarnación de distintos personajes que no son ella. Situación que la condujo a poner en tela de juicio el pensamiento racional y científico, el cual, al tiempo que la alimentaba, le creaba conflicto.

«Empecé a notar con cuánta frecuencia presentaban como consustancial a lo humano una voluntad de ir más allá en el espacio y el tiempo, que en definitiva implica considerar natural el domino de unos seres humanos sobre otros e incluso los conflictos fratricidas, aunque, eso sí, siempre enmascarado y justificado como fines superiores a alcanzar. Constaté también que ese era el sistema de valores que rige el comportamiento público, que alimenta la competitividad y agresividad necesarias para situarse profesional y políticamente, y que yo ponía en práctica más de los que me confesaba» (Amparo Moreno, 1993; p. 1).

El conflicto vital de Amparo Moreno es expresión y consecuencia del conflicto epistemológico y metodológico que encara el debate académico sobre la ciencia y sus prácticas en la actualidad. En el fondo de él, como lo sugiere ella misma, está la confrontación objetividad-subjetividad, sobre la cual varias teóricas se han pronunciado. Una de ellas es Evelyn Fox Keller, quien en el libro ya mencionado trata el tema con bastante profundidad y contribuye a explicar las relaciones entre esa confrontación y la 
establecida entre masculinidad y feminidad. Para ello se apoya en la génesis y usos de varios conceptos relacionados: género, autonomía, dominación, autoridad paterna, amor y poder.

Evelyn trata de describir la red de interacciones que existen entre el desarrollo del género, el sistema de creencias que equiparan objetividad con masculinidad y el conjunto de valores culturales, que simultánea y conjuntamente, han elevado a categoría superior lo definido como científico y lo definido como masculino. Lo que se ha supuesto como una diferencia intrínseca entre varón y mujer no es tal sino la representación que un sistema de creencias produce sobre el significado de lo masculino y lo femenino.

No obstante, esa asociación, históricamente omnipresente, entre masculino y objetivo $\mathrm{y}$, de manera más específica, entre masculino y científico, es un tema que la crítica académica se resiste a tomar en serio, denuncia Evelyn. Es viable pensar que tanto la composición de esa crítica como la lógica que la orienta hacen esa misión imposible y, con ello, más ardua la tarea de las académicas feministas.

Por eso Evelyn considera que es necesario aclarar y precisar el sistema de creencias en el que la ciencia adquiere género, pues éste ha llevado a su vez a la «generización de la ciencia». Tal aserto se refleja en el hecho de que, hasta ahora, la población científica ha sido una población arrolladoramente masculina, lo cual es más una consecuencia que una causa de la atribución de la masculinidad al pensamiento científico.

Así, cuando a las ciencias objetivas se las califica como «duras», como opuestas a otras ramas del conocimiento, denominadas «blandas», que quiere decir más subjetivas, lo que se hace implícitamente es invocar una metáfora sexual en la que "dura» es masculino y «blanda» es femenino. En general, se ha considerado que los hechos son duros, en tanto que los sentimientos son blandos.

Tal oposición se remonta a la historia de la división del mundo en dos zonas: la mente, que conoce, y la naturaleza o lo cognoscible. Para esa sectorización se prescribe una relación específica entre ambas zonas, así como las pasibles interacciones que pueden conducir a nexos entre ellas, es decir, que pueden llevar al conocimiento. De allí se asigna género a la mente y la naturaleza, pero además, al caracterizar el pensamiento científico y objetivo como masculino, la objetividad misma, por media de la cual el que conoce puede adquirir conocimiento, también es «generizada».

Desde esa óptica, la relación específica entre el que conoce y lo conocido es de distancia y separación; es la de un sujeto y un objeto radicalmente divididos, la que significa que es una relación no mundana en la que la naturaleza es objetivada, constituida en objeto. En concordancia con la división del mundo entre sujeto y objeto, hay una división de las formas de conocimiento en "objetivo» y subjetivo». La mente científica es separada de lo que hay que conocer, esto es, la naturaleza.

Para Evelyn Fox la tarea de explicar las asociaciones entre masculino y científico se convierte en la tarea de entender la subestructura emocional que vincula la experiencia del género con la experiencia cognitiva; se trata de orientarse hacia los procesos por los que se desarrolla la capacidad de pensamiento científico y las formas en que tales procesos se entrelazan con el desarrollo emocional y sexual. Según ella, las ideas sobre la diferencia entre los sexos exceden a lo que puede atribuirse a la biología y, una vez formadas, adquieren una vida propia que se sustenta en fuerzas culturales y psicológicas. 
La perspectiva de ello es que la capacidad de alcanzar objetividad, de delinear al sujeto con respecto al objeto, no es innata, aun cuando se tenga el potencial innato de objetividad. "Tal capacidad de percibir la realidad objetivamente es adquirida como parte inextricable del largo y doloroso proceso por el que se forma el sentido del yo en el niño» (Evelyn Fox, 1991, p. 89). No obstante, la aceptación de la separación de cada cual, el reconocimiento de la realidad independiente tanto del yo como del otro, no constituyen la culminación del desarrollo emocional, sino el comienzo y la precondición necesaria no solo para la ciencia sino también para el amor.

De lo anterior concluye Evelyn que la definición de objetividad heredada de la ciencia clásica, en la que se enraíza la premisa de que el sujeto puede y debe estar totalmente separado de la descripción del objeto, ha resultado eficaz en el pasado, pero el desarrollo contemporáneo de la filosofía y de la física ha demostrado su inadecuación epistemológica y la necesidad de pasar de la dicotomía clásica a una concepción más dinámica de la realidad y a una epistemología más sofisticada que le sirva de base.

\section{El desarrollo del género y la objetividad en Evelyn Fox Keller}

Continuando con Evelyn Fox, en una cultura como la nuestra, en la que se concede el valor primario a una ciencia basada en la premisa de una dicotomía radical entre el sujeto y el objeto, y en la que las demás experiencias son consideradas secundarias, aquellas primeras identificaciones a las que se ha dado el estatus "femenino» difícilmente pueden persistir Este aspecto es desarrollado por Evelyn de manera concisa en los siguientes términos:

El hecho de que para la mayoría sea la madre quien proporciona el contexto emocional a partir del cual se forja la discriminación entre el yo y el otro, lleva a un sesgamiento de nuestras percepciones de género. Dado que las experiencias más tempranas y apremiantes de fusión tienen origen en la relación madre-hija/o, parece inevitable que tal experiencia tienda a identificarse con «madre», mientras que la delineación y separación son experimentadas como la negación de «madre», como «no madre». La madre se convierte en un objeto y la niña o el niño en un sujeto, por un proceso que en sí mismo se transforma en oposición y negación de «madre».

Y, aunque más allá de la madre existe todo un mundo, en la constelación familiar resulta ser primariamente hacia el padre —o hacia la figura del padre - hacia donde se dirigirán la niña o el niño en busca de protección ante el miedo de ser engullida/o y ante la ansiedad o el miedo a la desintegración de su ego, aún frágil. El padre es quien va a representar la individuación y la diferenciación - la realidad objetiva misma-, quien puede representar el mundo «real» en virtud de que está en él. Desde Freud se ha entendido que los rudimentos del género, así como los de la realidad, se establecen mucho antes del período edípico y que la realidad queda personificada en el padre, por cuanto el primer lazo materno es experimentado como amenaza de ahogo, o pérdida de las fronteras del ego. Así es que, en todas las personas, las experiencias más tempranas conducen a asociar con lo masculino la postura afectiva y cognitiva de la objetivación, mientras que los procesos que implican borrar las fronteras entre sujeto y objeto tienden a ser asociados con lo femenino.

Por otra parte, aunque niños y niñas deben aprender por igual a distinguir el yo del otro y aunque tienen la misma necesidad de autonomía, en la medida en que los chicos sustentan su identidad sexual sobre una oposición con respecto a aquello que ala vez es 
experimentado y definido como femenino; es probable que el desarrollo de su identidad de género acentúe el proceso de separación. Este proceso se ahonda a medida que los chicos experimentan una doble «desidentificación respecto de la madre», la primera para establecer una identidad propia y la segunda para consolidar una identidad de género masculino, a lo cual añade más ímpetu la presión cultural tendiente a establecer una masculinidad estereotipada, que connota independencia y autonomía.

Se ha sugerido que el desarrollo en la chica de un sentido de la separación en cierta medida puede ser dañado por la identificación que experimenta con la madre. Aunque también ella deba desenmarañar su «yo» de las primeras experiencias de unicidad, sigue buscando en su madre el modelo de identidad de género y su necesidad de desidentificación no es tan radical. Pero además la fuerza de la cultura puede complicar más todavía el desarrollo de su autonomía al acentuar la dependencia y la subjetividad como características femeninas.

Lo que parece adecuado sugerir, a partir de lo anterior, es que un resultado posible de estos procesas es el de que los chicos puedan estar más inclinados hacia una delineación excesiva y las chicas hacia una delineación inadecuada, y que lleguen a convertirse en varones que tienen dificultades para amar y en mujeres que se retiran de la ciencia.

\section{La autonomía dinámica. Objetos en tanto que sujetos}

Para desarrollar el concepto de autonomía -otro de los pilares de la asociación objetividad-masculinidad-, Evelyn Fox recurre a sus reflexiones sobre el origen de la ciencia. Según tales ideas, Platón y Bacon serían los dos antepasados de la ciencia moderna más citados. Sin embargo, entre ambos existe una marcada diferencia, que parte del abismo que hay entre amor y poder. Mientras el conocedor platoniano busca «acercarse y unirse» a la naturaleza esencial de las cosas, guiado en su búsqueda por el eros puro, para el científico baconiano conocimiento equivale a poder y búsqueda de dominio sobre las cosas.

Ambas visiones de conocimiento se sustentan en imágenes castas de la sexualidad, pero hay diferencia entre ellas. Para Platón la castidad implica una demarcación entre el cuerpo y el alma; sirve para salvaguardar la pureza erótica de la relación de igual a igual entre la facultad mental y los objetos de conocimiento. En contraste, el «casto y legal maridaje» de Bacon, que ahora es entre mente masculina y naturaleza femenina, se constituye en metáfora de poder y dominación, al parecer diseñada para salvaguardar la integridad de quien conoce.

Es a través de su relación con la triada autonomía, masculinidad y objetividad como el poder logra la clave para la exploración de las relaciones complejas entre objetividad y dominación. Ese vínculo entre objetividad y dominación no es intrínseco a los propósitos de la ciencia, sino a los significados particulares que se asignan tanto al poder como a la objetividad. Las pretensiones cognitivas de la ciencia no tienen en sí mismas un origen objetivo, se desarrollan a partir de una subestructura emocional.

El científico no es tal cual, el observador puramente desapasionado que se ha idealizado, sino que es un ser que siente y cuya ambición de objetividad lleva consigo una profusión de significados subjetivos; luego, su mundo de objetos nunca deja de reflejar al sujeto.

Por eso mismo, la palabra autonomía está cargada de los prejuicios de la cultura occidental moderna, pues estos le imprimen una connotación de separación e 
independencia. La autonomía no es experiencia emocionalmente neutra; en la medida en que se constituye sobre la experiencia de la competencia, el sentido autónomo del yo constituye una profunda fuente de placer.

Evelyn define la autonomía como «el sentido psicológico de ser capaz de actuar según la volición de cada cual en lugar de hacerlo por control externo». Pero, para ella, existen dos concepciones de la autonomía: la estática y la dinámica.

En la concepción dinámica, la autonomía no cuestiona el «espacio potencial» entre el yo y el otro o la otra, es decir, el «área neutra de la experiencia» que permite la suspensión temporal de los límites entre «mi» y «no mi» que se requiere para cualquier experiencia empática; experiencia que permite el salto creativo entre conocedor y conocido. Recorre el vaivén entre sujeto y objeto como un prerrequisito tanto del amor como del conocimiento.

La autonomía dinámica refleja un sentido del yo que a la vez se relaciona y diferencia de los otros y las otras y un sentido de los otros y las otras, como sujetos con quienes se comparte lo suficiente para que puedan ser reconocidos sus intereses y sentimientos independientes; en resumen, deben poder ser reconocidos como otros sujetos. Al mismo tiempo, actuar sobre el mundo es actuar sobre los demás más o menos como uno mismo; pero se trata más de actuar en el mundo que de actuar sobre el mundo.

La autonomía estática, se manifiesta a través del control y la vigilancia como constantes reveladores; de hecho, traiciona sus propósitos. El control y la vigilancia reflejan, no tanto la inexistencia de confianza en la diferencia que uno guarda con respecto a los demás y las demás, cuanto la resistencia o repudio a ser igual; no hay un sentido de autoestima pero sí incertidumbre con respecto a la durabilidad del yo, y, en última instancia, no es tanto la seguridad que tenga cada cual en los límites de su ego sino la vulnerabilidad de éstos. Al respecto, David Shapiro, citado por Evelyn, describe esta situación como una postura de pseudo autonomía, que no es autonomía genuina si no expresión de autonomía estática.

Desde luego que, tal como lo expresa Evelyn, la autonomía, el control y la dominación hacen parte de una secuencia que en sí misma no corresponde a lo masculino o lo femenino, pues tanto hombres como mujeres se enfrentan a la búsqueda de un sentido del yo, la autonomía y la intimidad. Para los dos sexos la posibilidad de sacar placer de la autonomía del otro o la otra evidencia un sentido del yo definido en relación y diferenciación simultánea de los otros y las otras. Por ese motivo, la definición cultural de lo masculino y lo femenino como opuestos polares, con base, uno en la diferencia y otro en la similitud, va en contra del desarrollo de la autonomía dinámica en ambos sexos. Al tiempo que lleva a una exclusión, por una parte, de la continuidad y, por otra, de la diferenciación, siendo ambas exclusiones igualmente enemigas del reconocimiento de la intersubjetividad.

\section{La autoridad paterna}

Otro pilar de la relación objetividad-masculinidad está relacionado con el concepto de autoridad paterna, de origen freudiano. Concepto que Evelyn Fox recrea desde una perspectiva cognitiva.

Evelyn nos remonta al esquema según el cual, para niños y niñas, los encuentros con la autoridad adulta, en particular con los padres -intrusos-, pueden convertirse en 
luchas de la voluntad. En la teoría psicoanalítica tradicional se considera que la intervención del padre en la diada madre-hijo/a es esencial para la diferenciación, y que, en tanto que opuesto a la madre, su intervención es especialmente vital para el niño.

En consecuencia, al introducir una imagen alternativa de poder a la que sí puede aspirar el niño, el padre ofrece a su hijo un tipo muy especial de resolución a la tensión de la diada madre-hijo y una solución particular a las amenazas a su autonomía que se derivan tanto del atractivo del amor como de la intrusión del poder materno.

Esta solución es una nueva concepción de la autonomía, basada ahora, no en el reconocimiento, el placer y el respeto mutuos sino en la asimilación con el poder paterno legítimo. No solo se rompe la unidad dialéctica de diferenciación y conexión, sino que ahora el sentido de la diferencia queda asegurado por la introducción de un nuevo tipo de relación.

Además, mediante la identificación con el padre se le está ofreciendo al hijo, en lugar del atractivo de la intimidad materna, la perspectiva futura del dominio sobre lo materno. Sin embargo, el significado de esta intervención paterna no depende simplemente de la autoridad del padre sino también de la deslegitimación de la autoridad materna y las deformaciones resultantes del ejercicio de la maternidad, y es posible que esta autoridad paterna no se imponga simplemente sino que sea buscada.

La bifurcación entre autoridad paterna y poder materno incide en el desarrollo de la identidad de género: cuanto mayor sea la oposición entre autonomía y dependencia, más grande será el vacío entre masculino y femenino. Y, con impulso de la definición estática de autonomía aludida, también queda definido el concepto de poder con legitimidad ubicado en el falo, mientras el poder de la madre es neutralizado, primero por la deslegitimación y, en última instancia, por la negación. En consecuencia, dominación y sumisión son actividades gemelas, sustitutas ambas de la diferenciación verdadera y de la autonomía dinámica.

\section{Contrapartidas cognitivas de la dinámica emocional}

Evelyn Fox continúa señalando que la naturaleza humana es tal, que la tensión entre autonomía e intimidad, separación y conexión, agresión y amor, es insoluble, aunque recuerda que tensión no es lo mismo que oposición. Para Evelyn el propósito es entender la forma en que nuestra experiencia psicosocial, sobre todo la disyunción entre masculino y femenino, conduce a una bifurcación entre autonomía e intimidad, separación y conexión, poder y amor.

Desde Bacon, el conocimiento proporciona poder, pero también proporciona entendimiento, que es la forma distintivamente humana de descubrir conexiones en el mundo, y, desde uno u otro sentido, parece confirmarse la existencia de la relación entre conocimiento y sexualidad. Por eso Evelyn define la oposición entre amor y conocimiento como la expresión cognitiva de la oposición entre amor y poder, y la considera disyunción central para el desarrollo de la ciencia moderna y para la construcción del varón occidental, que por lo tanto hace siniestra la ecuación entre conocimiento y poder, al permitir que la objetividad quede contaminada por la dominación.

La autora se centra en el análisis de la interacción entre experiencia emocional y experiencia cognitiva, y analiza la interacción entre el desarrollo del sentido del yo en mujeres y hombres, así como el sentido de la realidad. Busca comprender el modo en que 
el significado que se asigna a la objetividad refleja nuestra forma de entender la autonomía, y cómo aquél puede estar determinado por ella. Con este fin considera útil introducir dos concepciones de objetividad: dinámica y estática.

Define la objetividad como "búsqueda de un entendimiento del mundo que nos rodea que sea lo más auténtico posible y que, por ello, sea lo más fiable posible". Esta búsqueda será dinámica en la medida en que, como fuente de ese entendimiento, recurre de forma activa a los elementos comunes que se presentan entre mente y naturaleza. La objetividad dinámica tiende a una forma de conocimiento que garantiza la integridad independiente del mundo que nos rodea, al mismo tiempo que sigue siendo consciente de nuestra conectividad con ese mundo.

Llama objetividad estática a la búsqueda de un conocimiento que empieza por la separación entre el sujeto y el objeto, en lugar de intentar desenmarañar la unión que se produce entre uno y otro.

La objetividad dinámica es una búsqueda de conocimiento que hace uso de la experiencia subjetiva. Tomando como premisa la continuidad, reconoce la diferencia entre yo y el otro u otra como una oportunidad para una relación más profunda y articulada. En ese sentido, se considera que la lucha por desenmarañar al yo del otro o de la otra es en sí misma una fuente potencial de inserción de la naturaleza del yo y del otro u otra.

Con este fin, el científico emplearía una forma de unión hacia el mundo natural que se asemejaría al ideal de atención hacia el mundo humano, como una forma de amor. La capacidad para tener esa atención requiere un sentido del yo que sea lo suficientemente seguro como para tolerar tanto la diferencia como la continuidad, y presupone el desarrollo de una autonomía dinámica. El propósito de tales actividades-afecto no es deshacer conexiones sino establecer relaciones con el entorno humano y natural.

Las herramientas preceptúales que se desarrollan para cumplementar ese interés por el mundo forman parte de lo que Schachtel (citado por Evelyn) denomina percepción «alocéntrica» (centrada en los otros). Esta exige que todas las facultades perceptivas y experienciales de quien percibe se centren por completo en el objeto, para que pueda ser experimentado de la forma más completa posible. Se constituye así una forma de atención que a su vez presupone un eclipse temporal de todos los pensamientos y luchas egocéntricas de quien percibe, de todas las preocupaciones por el yo y por la autoestima. Ello implica una unicidad que no lleva a una pérdida del yo sino a un sentimiento más fuerte de estar vivo.

La percepción alocéntrica es percepción al servicio de un amor que quiere afirmar a los otros en su ser total y único. Es una afirmación de los objetos como parte del mismo mundo del que se forma parte. En contraste con la percepción autocéntrica, dominada por la necesidad o el auto interés, permite un entendimiento más pleno y global de objeto en sí mismo. La capacidad para emplear este tipo de atención requiere, por lo tanto, el desarrollo de la capacidad de distinguir entre yo y el otro.

Schachtel describe así una relación con los objetos que es característica del objetivismo en general. Separar al sujeto del objeto sería negar la realización experimentadora de la relación entre sí mismo y el otro, que constituye la esencia de la objetividad dinámica necesaria para la percepción de un objeto en sí mismo.

Un individuo obsesivo-compulsivo centrará su interés en el control, no tanto de los otros como de sí mismo, sometiendo al mismo tipo de control la atención y centrándose de 
manera muy intensa, aguda y restringida, con lo cual impide la visión periférica, la impresión fugaz, el impulso y la sensación general del objeto. En otro sentido, la atención del paranoide será el temor de ser controlado por los demás, y la basará en el desea de dominación.

Tales distorsiones se expresan en la agresión retórica común que caracteriza a la ciencia y que la asume como "un esfuerzo por dominar la naturaleza», un "tomar par asalto sus fortalezas y castillos», lo que suena como un campo de batalla. De la misma manera, los problemas deben ser «atacados», «conquistados», «azotados».

Lo que Evelyn define como contrapartida cognitiva de la dinámica emocional se basa en el hecho de que la ciencia que se enuncia a sí misma con la promesa de una separación fría y objetiva de su objeto de estudio selecciona a un tipo de individuos para quienes esta promesa supone un consuelo emocional, que una ciencia que promete poder y el ejercicio del dominio sobre la naturaleza selecciona a aquellos individuos para quienes el poder y el control constituyen preocupaciones centrales. Igualmente, una ciencia que concibe la búsqueda de conocimiento como un proceso de adversidad, selecciona a quienes tienden a sentirse en una relación de adversidad con su entorno natural. Las conexiones entre estos tres componentes de la ideología científica no radican en su cohesión intelectual sino en la cohesión de las necesidades emocionales a las que recurren.

La necesidad de dominar la naturaleza es una proyección de la necesidad de dominar a otros seres humanos y no surge tanto del poder que se tenga sino de la ansiedad que causa el miedo a la impotencia. Afortunadamente, la práctica de la ciencia es de hecho muy diferente de sus prescripciones ideológicas; científicas y científicos difieren en el enfoque que dan a sus trabajos y en su estilo de trabajo.

En síntesis, la retórica de la dominación, la coerción y el poder sirve para seleccionar un tipo de comunidad científica que tiende a exhibir estilos emocionales y cognitivos particulares. Esa misma retórica, interiorizada por la comunidad, selecciona a su vez a estilos de trabajo, metodologías e incluso ideologías que sean compatibles con ella. La generalización de la ciencia, en tanto que empresa, dominio intelectual, y visión del mundo está reflejando y perpetuando esos esquemas, que, como se ha visto, provienen de asociaciones hechas desde épocas anteriores.

Este punto de vista conduce a Amparo Moreno y seguramente a otras muchas $Y$ investigadoras al estado de esquizofrenia que expresa en el artículo mencionado, pues, tal como lo afirma ella misma, la noción de lo humano habitual en los textos más diversos del discurso lógico-científico, el concepto de hombre a partir del cual se articula nuestra racionalidad, implican valorar como superior todo cuanto se orienta hacia la voluntad de dominar el mundo, menospreciando como inferior y caótico - y violentando y ahogandolas aspiraciones al entendimiento gratuito. Este presupuesto de la voluntad de dominio vicia, según Amparo, las reflexiones académicas, políticas e informativas.

A partir del periodismo y la academia universitaria, Amparo Moreno Sarda trabaja sobre la necesidad de lecturas no androcéntricas de los textos académicos, para develar las articulaciones del sistema de valoraciones positivas de la racionalidad, que conducen a académicas y académicos a relacionar inconscientemente lo que se argumenta con lo que se siente, en la base de lo cual está un sistema simbólico que justifica pormenorizadamente dónde, cuándo, cómo, qué y para qué debe ser lo que se ha aprendido a creer que debe ser, y que se ha engarzado con otro sistema mítico-religioso, 
según el cual se identifica como concepto de lo humano todo cuanto solo puede atribuirse al universo mental y al sistema de valores de los actores públicos, que actúan al ritmo de la voluntad de dominar el mundo. Se trata de un modelo viril, que actúa como modelo ideal del yo, como patrón de pensamiento racional, como yo consciente al que se le ha atribuido un conocimiento objetivo, que bloquea otros pensamientos que deben ser rechazados como irracionales.

Para Luisa Muraro (1996), el subjetivismo "típicamente femenino" indica la diferencia sexual desde la parte del sujeto, señalándola como algo no legítimo, no inscribible en el orden simbólico. En cuanto tal ha sido recuperado por la «política de las mujeres», que lo ha transformado prácticamente en un principio de conocimiento del mundo y de transformación del orden simbólico, con la instancia del «partir de si», que quiere decir no opinar ni decidir nunca sin haber establecido dónde estoy yo con respecto a la materia a juzgar o decidir, yo con la que soy y quiero llegar a ser, yo en relación con otras y otros.

Luisa destaca la propuesta de Lucy Irigaray de superar la oposición realismosubjetivismo femenina, y cambia el significado del subjetivismo femenino, que en la sociedad patriarcal ha entrañado mantener el deseo femenino de estar en el mundo con vida y vinculado a hacer que el lugar del Otro no esté, para una mujer, nunca vacío, y se ponga siempre a alguien, a uno cualquiera, en el lugar del Otro. A su vez, define el realismo femenino como la «capacidad femenina de experimentar y gozar de un mundo que no existe, de exceder, de asomarse fuera del mundo que existe; capacidad que, de otro modo, oscila ciegamente entre ilusión y autenticidad, a merced del juicio del otro; para ejercerse como potencia libre del pensamiento necesita criterios de verdad» (Luisa Muraro, 1996, p. 87).

Luisa Muraro destaca a filósofas como Simone Weil, Edith Stein, Hannah Arendt, Clarice Lispector, Gertrude Stein y Elsa Morante -que no llevan nombre de filósofas porque están fuera del recinto filosófico-, quienes sustentan la posibilidad de un conocimiento objetivo, basado en la no reductividad del pensamiento al Yo y acompañado

por el concepto de una subjetividad no opuesta a la objetividad sino puesta para dar lugar al mundo del cual el sujeto se conocerá entonces como parte.

Helen E. Longino (1996) también hace una crítica a lo que denomina virtudes teóricas, que son aquellos rasgos de una teoría o modelo que cuentan prima facie como razones suficientes para apoyarla, apreciarla o aprobarla. Señala la existencia de un conjunto de tales virtudes, llamadas "valores cognitivos», estipuladas en escritos filosóficos sobre las ciencias, y determina las propiedades de las teorías que las hacen ser consideradas como conocimiento. Helen argumenta que no son cognitivas y que pueden ser vehículo para la importación del género y las ideologías de este.

Apoya su análisis en los cinco valores definidos por Thomas Khun, que recogen los establecidos por otros teóricos de la ciencia convencional: precisión, simplicidad. consistencia interna y externa, amplitud de alcance y fecundidad. A estas virtudes (de las que queda claro no se crearán todas simultáneamente y con la misma intensidad, por lo cual los debates al respecto son múltiples) agrega Helen la pregunta sobre la posibilidad de otras alternativas.

Para ello revela los objetivos diferentes, señalados a la ciencia en los escritos feministas, donde se encuentran otros valores, como adecuación empírica, novedad, heterogeneidad ontológica, interacción mutua, aplicabilidad a las necesidades humanas corrientes y difusión del poder. 
La adecuación empírica es apreciada por su capacidad para guiar la investigación y revelar tanto el género en los fenómenos como los prejuicios genéricos en la consideración de los mismos. Por novedosos se entienden modelos o teorías que difieren, de manera significativa, de las teorías aceptadas y adoptan principios explicativos distintos (Sandra Harding, Donna Haraway). Una teoría caracterizada por heterogeneidad ontológica otorga paridad a diferentes tipos de entidades (Jeanne Altmann). La interacción mutua valora las teorías que tratan como mutuas a las relaciones entre las entidades y los procesos (Evelyn Keller, Barbara McClintock). La aplicabilidad a las necesidades humanas corrientes y la difusión del poder son criterios pragmáticos, más relevantes en las decisiones sobre qué teorías o marcos de trabajo atender.

Con el desarrollo de estos valores la autora no pretende afirmar que las virtudes tradicionales son siempre políticamente agresivas, pero sí que, de hecho, en algún momento son significados que no se pueden tratar como bases neutrales de los juicios.

Tratar las virtudes corrientes como constitutivas de la ciencia tiene como consecuencias: a) restringir las formas en las que se puede entender el mundo por la ocultación de la legitimación de modelos o teorías que exhiben las virtudes alternativas; b) cegar la ciencia ante las dimensiones políticas del conocimiento; c) restringir quién participará en la construcción del conocimiento acerca del mundo por devaluar asuntos e intereses que se desvían de los corrientes.

Como colofón vale mencionar el llamado de María Zambrano (citada por Elena Laurenzi en la introducción a María Zambrano. Nacer por sí misma, 1995), sobre la necesidad de aproximar el intelecto al sentir, al que considera el fundamento de todo conocimiento humano, signo supremo de veracidad, de verdad viva. Para ser realmente «viviente», la filosofía debería romper la hegemonía de la mente y prestar atención al ser humano en su totalidad, explorando la inteligencia del cuerpo y del corazón, «el logos que se reparte en las entrañas».

\section{Bibliografía}

Cigarini Lia. 1996. La política del deseo: la diferencia femenina se hace historia. Barcelona, Icaria.

Fox Keller Evelyn, 1991. Reflexiones sobre género y ciencia. Valencia, Alfons el Magnanim.

Hammonds Evelynn M., 1996. ¿Existe una ciencia feminista? Mujeres de ciencias. Mujer, feminismo y ciencias naturales, experimentales y tecnológicas. Granada, Servicio de Publicaciones de la Universidad de Granada.

Laurenzi Elena, 1995. "introducción” a María Zambrano. Nacer por sí misma. Madrid, horas y HORAS.

Longino Helen E.. 1996. Haciendo visible el género en la construcción del conocimiento científico. Memorias del Seminario Ciencia y Feminismo. U. Complutense, Madrid. Moreno Sarda Amparo, 1993. "La subjetividad oculta de la objetividad o la esquizofrenia académica». DUODA Revista d'Estudis Feministes, N ${ }^{0} 4$, p. 15-29. Barcelona, Centre d' Investigació Historica de la Dona. Universidad de Barcelona. 
Muraro Luisa. 1996. Nuestra capacidad común de infinito: traer al mundo el mundo. Barcelona, Icaria

Rivera Garretas María Milagros, 1990. "Christine de Pizán; la utopía de un espacio separado". Textos y espacios de mujeres, Barcelona, Icaria.

1997. Oliva Sabuco de Nantes Barrera. Breve historia feminista de la literatura española (en lengua castellana). La literatura escrita por mujer (de la Edad Media al siglo XVIII). Barcelona, Anthropos.

Solterer Helen, 1995, Christine's Way: The Querelle du Roman de la Rose and $t$ Ethics a Polítical Response. The Master and Minerva. Disputing Women in French Medieval Culture. Berkeley, The University of California Press.

Wade Labarge Margaret, 1996. La mujer en la Edad Media. Madrid, Nerea. 